\title{
Spatio-temporal dynamics of global H5N1 outbreaks match bird migration patterns
}

\author{
Yali Si ${ }^{1,2,4}$, Andrew K. Skidmore ${ }^{1,2}$, Tiejun Wang ${ }^{1}$, Willem F. de Boer ${ }^{2}$, Pravesh Debba ${ }^{3}$, \\ Albert G. Toxopeus ${ }^{1}$, Lin $\mathrm{Li}^{4}$, Herbert H.T. Prins ${ }^{2}$ \\ ${ }^{1}$ Department of Natural Resources, International Institute for Geo-information Science and Earth \\ Observation (ITC), Hengelosestraat 99, P.O. Box 6, 7500AA Enschede, The Netherlands; ${ }^{2}$ Resource \\ Ecology Group, Wageningen University, Droevendaalsesteeg 3a, 6708 PB Wageningen, The Netherlands; \\ ${ }^{3}$ Logistics and Quantitative Methods, Council for Scientific and Industrial Research, CSIR Built \\ Environment, P.O. Box 395, 0001 Pretoria, South Africa; ${ }^{4}$ School of Resources and Environmental Science, \\ Wuhan University, Luoyu Road 129, 430079 Wuhan, People's Republic of China
}

\begin{abstract}
The global spread of highly pathogenic avian influenza H5N1 in poultry, wild birds and humans, poses a significant pandemic threat and a serious public health risk. An efficient surveillance and disease control system relies on the understanding of the dispersion patterns and spreading mechanisms of the virus. A space-time cluster analysis of H5N1 outbreaks was used to identify spatio-temporal patterns at a global scale and over an extended period of time. Potential mechanisms explaining the spread of the H5N1 virus, and the role of wild birds, were analyzed. Between December 2003 and December 2006, three global epidemic phases of H5N1 influenza were identified. These H5N1 outbreaks showed a clear seasonal pattern, with a high density of outbreaks in winter and early spring (i.e., October to March). In phase I and II only the East Asia Australian flyway was affected. During phase III, the H5N1 viruses started to appear in four other flyways: the Central Asian flyway, the Black Sea Mediterranean flyway, the East Atlantic flyway and the East Africa West Asian flyway. Six disease cluster patterns along these flyways were found to be associated with the seasonal migration of wild birds. The spread of the H5N1 virus, as demonstrated by the space-time clusters, was associated with the patterns of migration of wild birds. Wild birds may therefore play an important role in the spread of H5N1 over long distances. Disease clusters were also detected at sites where wild birds are known to overwinter and at times when migratory birds were present. This leads to the suggestion that wild birds may also be involved in spreading the H5N1 virus over short distances.
\end{abstract}

Keywords: H5N1, space-time cluster, migratory waterbirds, wetlands.

\section{Introduction}

The highly pathogenic avian influenza H5N1 virus is a highly pathogenic strain of the influenza $\mathrm{A}$ virus, which can cause systemic disease, resulting in high mortality in bird populations (Swayne and

Corresponding author:

Yali Si

Department of Natural Resources, International Institute for

Geo-information Science and Earth Observation (ITC)

Hengelosestraat 99, P.O. Box 6, 7500AA Enschede

The Netherlands

Tel. +31534874 559; Fax +31534874338

E-mail: yali@itc.nl
Halvorson 2003; Swayne and King 2003), and which can also infect humans and many other animal species (Cardona et al., 2009). The virus was detected for the first time in farmed geese in southern China in 1996 (Xu et al., 1999). The first case of a human becoming infected with the H5N1 virus was documented in Hong Kong in 1997 (Subbarao and Katz, 2000). The present outbreak of H5N1 began in December 2003, when South Korea identified the virus in poultry populations (Lee et al., 2005). The virus circulated in east and southeast Asia during 2003 and 2004. In May 2005, the first $\mathrm{H} 5 \mathrm{~N} 1$ outbreak in migratory waterfowl was detect- 
ed at the Qinghai Lake in western China (Chen et al., 2005, 2006; Liu et al., 2005). In July 2005, the virus was detected in Russia, and it arrived in Romania in October 2005 (Gilbert et al., 2006b). Africa reported its first emergence of $\mathrm{H} 5 \mathrm{~N} 1$ in Nigeria in February 2006 (Ducatez et al., 2006). This global H5N1 epidemic continues to date and has raised many questions. It is important to find out what the dispersion patterns of the virus are. Subsequently, which mechanisms are responsible for the observed patterns, and more specifically, do migratory birds play a role in the global H5N1 transmission?

A number of studies have been undertaken to answer these questions. The worldwide avian influenza activity has been summarized (Alexander, 2007; Yee et al., 2009). Descriptive methods have been used to analyse the spread of H5N1 outbreaks (Tiensin et al., 2005; Gilbert et al., 2006b). Phylogenetic analyses of the lineage relationship were executed on the virus strains isolated in eastern Asia (Li et al., 2004), South Korea (Lee et al., 2008), Nigeria (Ducatez et al., 2006) and western Africa (Ducatez et al., 2007). Local level space-time cluster analyses of $\mathrm{H} 5 \mathrm{~N} 1$ outbreaks over short time periods have been carried out in China (Oyana et al., 2006), Vietnam (Pfeiffer et al., 2007) and Romania (Ward et al., 2008). The purpose of these studies was to identify spatio-temporal patterns of the spread of the disease and to ascertain possible underlying mechanisms. A study, covering an extended period of time on a global scale, has not been undertaken to date, though this is important if knowledge is to be gained on the worldwide spread of the H5N1 virus. Previous studies (Kilpatrick et al., 2006; Gilbert et al., 2008) suggested that the movements of wild birds and domestic poultry were the suspected agents for spreading the virus. Poultry transportation and the wild bird trade were also suspected agents. Their role in spreading the H5N1 virus is relatively easy to track and detect, by analysing trade data (Kilpatrick et al., 2006). However, to what extent migratory waterbirds can be regarded as the cause of the virus spread is still under investi- gation (Feare and Yasué, 2006; Normile, 2006).

Some studies have questioned the role of wild birds in spreading the H5N1 virus. Weber and Stilianakis (2007) indicated that it is implausible for an infected bird to migrate over long distances, as migration leads to immunosuppression and is negatively affected by virus infection. Feare and Yasué (2006) questioned an experiment of asymptomatic infection of wild birds with H5N1, due to challenges of sample species identification and capture methods. Also, even though large numbers of birds migrate through the East Atlantic flyway and East Asian Australian flyway, the disease currently only circulates in Eurasia and Africa, without further spread to America and Australia. This suggests that migratory birds may not be responsible for the longdistance spread of the H5N1 virus.

A number of studies, however, do suggest wild birds may spread the H5N1 virus. Chen et al. (2004) indicated that ducks can carry the H5N1 virus asymptomatically. Gilbert et al. (2006b) detected that the directions in which the disease spread, were consistent with the major bird migration routes in the western Palaearctic. Brown et al. (2008) observed that swans and geese can shed $\mathrm{H} 5 \mathrm{~N} 1$ virus before and after the onset of clinical signs, on the basis of an experimental infection of H5N1 virus. Keawcharoen et al. (2008) found that some wild duck species showed abundant virus excretion without clinical or pathologic evidence of debilitating disease, and therefore could potentially be long-distance vectors of H5N1.

If $\mathrm{H} 5 \mathrm{~N} 1$ is spread by wild birds, either over long or over short distances, this might be deduced from spatial-temporal patterns of the disease outbreaks (Onozuka and Hagihara, 2008; Ward et al., 2008). Wild birds utilize large number of over-staging sites along the flyways to forage during the migration, and settle in breeding and wintering sites during the non-migration seasons. This behaviour determines a potential role of wild birds in H5N1 spread over long and short distances, which requires both regional and local disease patterns to be generated. Due to intercontinental bird migration and the 
international trade of fowl, the role of wild birds as disease vectors should be viewed on a global scale (Kilpatrick et al., 2006). This study was designed to throw light on the role of wild birds in spreading $\mathrm{H} 5 \mathrm{~N} 1$ viruses. The objectives of this study were to identify the spatio-temporal patterns and dynamics of H5N1 outbreaks on a global scale, and to further deduce the role of wild birds in the worldwide transmission of $\mathrm{H} 5 \mathrm{~N} 1$ over long and short distances.

\section{Materials and methods}

The main reservoirs of avian influenza are considered to be waterbirds, such as duck, geese, swan, gulls, terns and shorebirds (Webster et al., 1992; Alexander, 2000; Suarez, 2000; Olsen et al., 2006). Therefore, the possible role of migratory birds in spreading the H5N1 virus was examined by comparing the spatio-temporal dynamics of the disease clusters with the timing, location and direction of the major waterbird migration flyways. A flyway is the entire range a migratory bird species (or groups of related species or distinct populations of a single species), uses when moving on an annual basis from their breeding grounds to non-breeding areas and back, including intermediate resting and feeding places (Boere and Stroud, 2006). Figure 1 depicts the eight broadly grouped flyways of waterbirds, adapted from information collected and analyzed by the International Wader Study Group (Asia-Pacific Migratory Waterbird Conservation Committee, 2001; Stroud et al., 2004). In each flyway, the spring migration passes in a northward direction and the autumn migration passes in a southward direction. The migratory direction is defined based on the eight waterbird flyways, omitting the complexity of the migration strategies and systems of individual waterbird species (Boere and Stroud, 2006). Such attempts to simplify the main migration routes may lose information, for example, an important component of east-west migration in Eurasia is exclud-

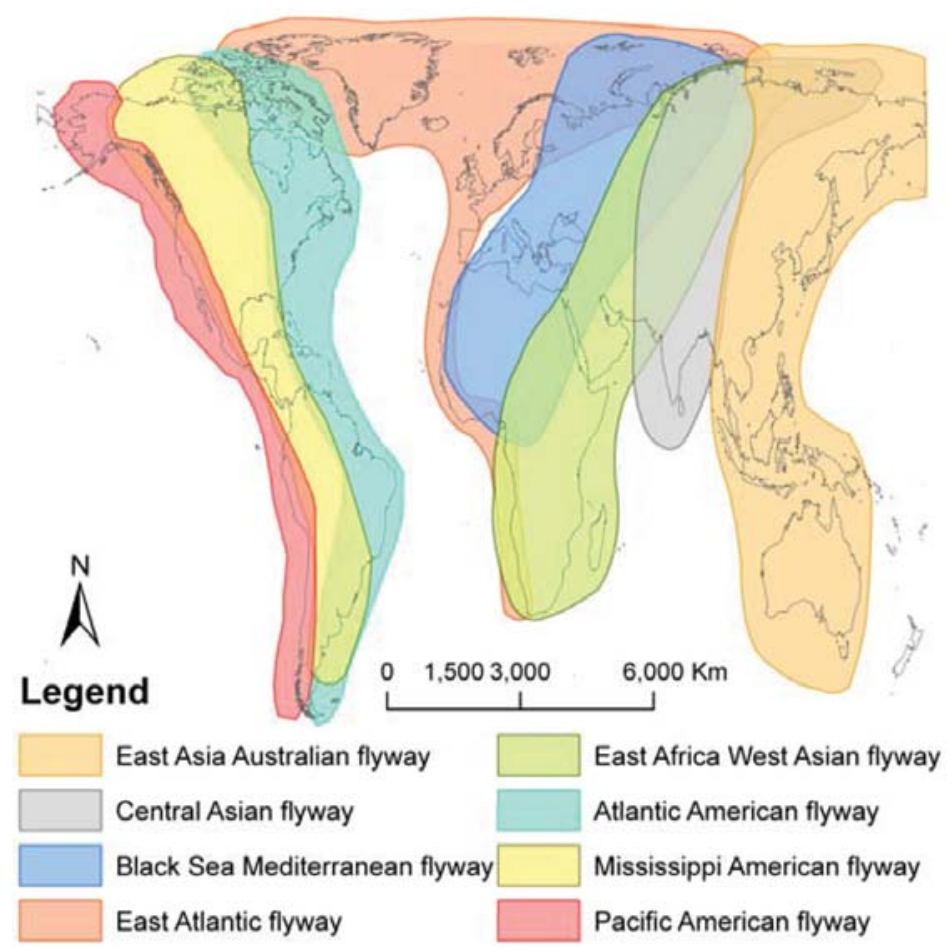

Fig. 1. Eight broad flyways of migratory waterbirds (source: International Wader Study Group). 
ed in the above flyways (Scott and Rose, 1996; Boere and Stroud, 2006). These limitations are considered when interpreting the results. On the other hand, strong relationships between the spread of avian influenza and the major bird migratory routes would suggest a role.

\section{Data}

The time-location series of $\mathrm{H} 5 \mathrm{~N} 1$ outbreaks were extracted from official reports provided by the World Organization for Animal Health (OIE) (http://www.oie.int). Each report contained the following attributes: province, district, sub-district, type of epidemiological unit, location, latitude, longitude, start time, end time, affected species, as well as the number of susceptible cases, deaths, destroyed and slaughtered animals. However, from December 2003 to December 2005, most Southeast Asian reports (mainly in Thailand and Vietnam) lacked latitude and longitude. In this study, the locations of these outbreaks were geocoded on the basis of the information provided in the reports, using the centre of the specific administrative region involved. The average area of the largest administrative division (province) in Thailand and Vietnam is $6,716 \mathrm{~km}^{2}$, equal to an area with a radius of approximately 46 $\mathrm{km}$. Hence, some of the clusters detected (radius $<46 \mathrm{~km}$ ) in Southeast Asia during this stage, may suffer from a bias in geocoding, as the original location of the outbreaks may have been located somewhere else (maximum $46 \mathrm{~km}$ error) than the centroid of the administration division.

Three years of $\mathrm{H} 5 \mathrm{~N} 1$ outbreak data were used, from December 2003 to December 2006. Both Australian and American continents were omitted from the map because of no report of highly pathogenic avian influenza H5N1 outbreaks to date (Pei et al., 2009; Yee et al., 2009). Figure 2a shows the locations of the outbreaks. The outbreaks were all concentrated in south and southeast Asia during 2003 and 2004. In 2005, outbreaks continued to be reported in Asia, but also started to occur in western Russia and Europe. In 2006, the disease became pandemic around the Black Sea region, the Mediterranean region, western Europe and eastern Africa. Figure $2 b$ shows the locations of two different types of outbreaks (i.e., in wild birds and in poultry). Wild bird outbreaks were concentrated in western Europe, with sporadic outbreaks being observed in southern Europe and central Asia. Poultry outbreaks, however, were concentrated in southeast Asia (together with wild bird outbreaks and a few mixed outbreaks), western Russia, the Black Sea region, Arabia and Africa. As Figure 2 is displayed for visualization, some specific outbreaks could be invisible because of overlap with other outbreaks, such as the wild bird H5N1 outbreak occurrence in Egypt in February 2006.

\section{Epidemic curves}

To display the outbreaks' magnitude and trend over time, epidemic curves were constructed by counting weekly numbers of outbreaks from 2003 to 2006 in Asia, Europe and Africa. Because the incubation period (i.e., the length of time between exposure and onset of symptoms) for avian influen$\mathrm{za}$ is about 21 days (OIE, 2005), the time unit on the $x$-axis was defined as 7 days, equalling one-third of the incubation period (CDC, 2008). The incubation period can be shorter, depending on the species and exposure conditions (WHO, 2006).

\section{Space-time permutation model}

The space-time permutation model in scan statistics has been used to test for spatio-temporal clusters, and to identify their approximate location and timing (Kulldorff et al., 2005). Space-time clusters occur when an excess number of H5N1 outbreaks are observed, within a user defined spatial and temporal range. Disease spread is strongly influenced by the spatial and temporal behaviour of the population at risk. The H5N1 outbreaks are of concern to multiple populations (i.e., poultry, wild bird and human), which do not always have a clearly defined distribution, like wild birds. The advantage of the 

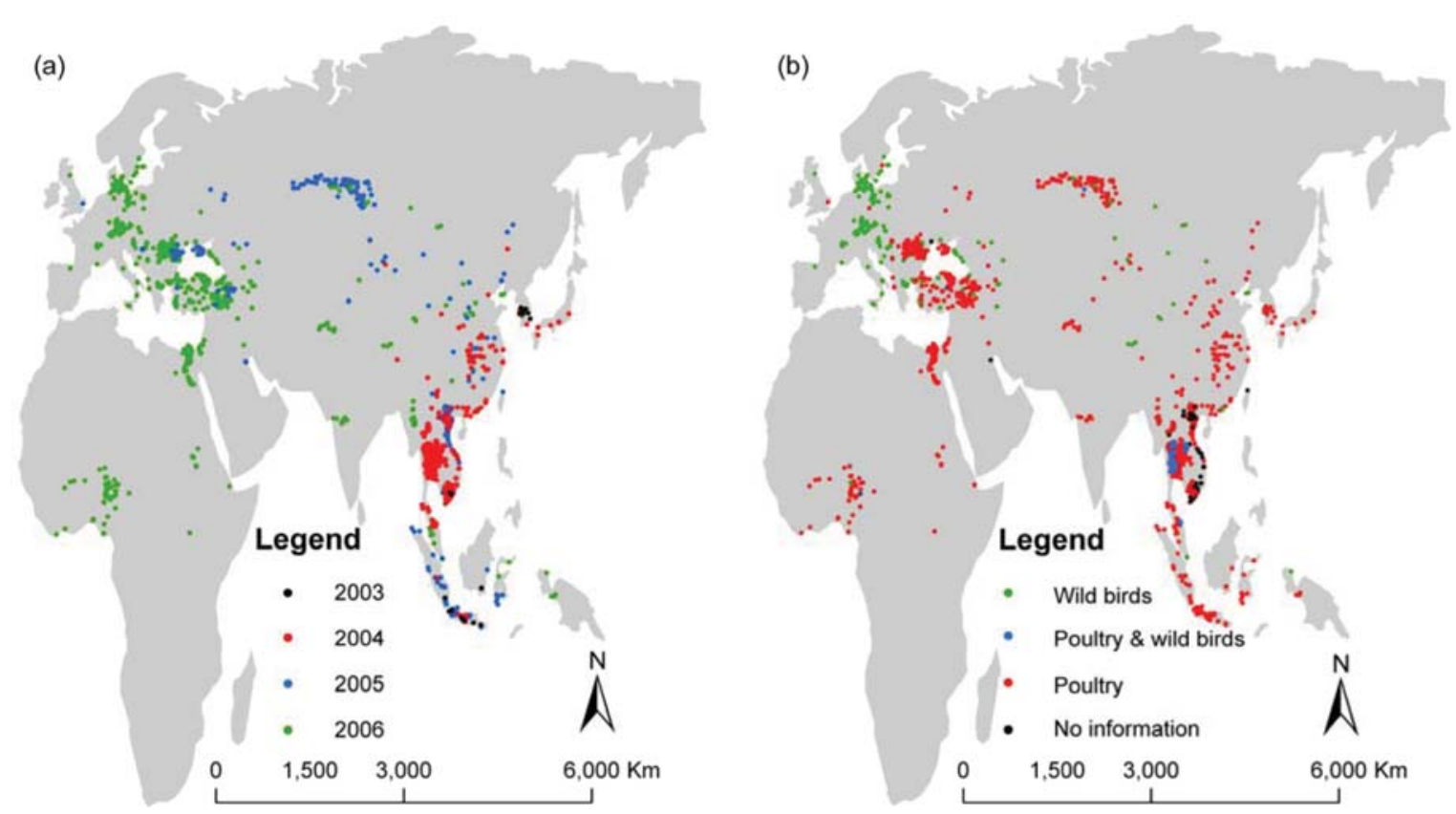

Fig. 2. Worldwide distribution of H5N1 outbreaks from December 2003 to December 2006, displayed by year (a) and by type of population (poultry or wild birds) (b).

space-time permutation model is, that it only requires actual H5N1 outbreak data (Kulldorff et al., 2005). The space-time permutation model does require the population at risk to be constant, so short analysis periods were selected in order to respect this requirement (Kulldorff, 2006). The disease patterns of the different epidemic phases, were therefore, analysed separately, using the space-time permutation model and SaTScan software (http://www.satscan.org). The populations involved (i.e., the number of bird flocks, farms and villages) could then be assumed to be constant for each epidemic phase.

The space-time permutation model analyzes clusters of H5N1 outbreaks both spatially and temporally, by testing whether outbreaks that are close in space are also close in time (Kulldorff, 2006). In the permutation model, the scanning window forms a cylinder with the base representing space and the height representing time. The cylinder begins as a single point, gradually increasing both in diameter and in height, from zero to some maximum value, defined by the user. The expected number of outbreaks was calculated on the basis of the null hypothesis, assuming complete spatial randomness, which is synonymous with assuming that the observed outbreaks were approximately independent Poisson random variables with a constant mean (Diggle, 2003). Based on this approximation, a likelihood ratio was measured to determine whether the cylinder contained a cluster or not. Of all the cylinders evaluated, the one with the maximum likelihood is considered to be the primary candidate for a true cluster (Kulldorff et al., 2005). Statistical significance of detected clusters was evaluated using a Monte Carlo simulation (Dwass, 1957). The test P-value was estimated by comparing the rank of the maximum likelihood from the real data set, with the maximum likelihood from the random data sets, defined as $\mathrm{P}=$ rank / $(1+$ number of simulations) (Dwass, 1957; Kulldorff, 2006). A detailed description and application of space-time permutation scan statistics can be found in other publications (Kulldorff et al., 2005; Pearl et al., 2006; Cooper et al., 2008). 


\section{Input parameters}

The maximum spatial scanning window should not exceed $50 \%$ of all outbreaks, because otherwise an extremely low outbreak rate outside the scanning window may not be detected by the algorithm (Kulldorff, 2006). Two maximum spatial scanning windows were chosen for this analysis. One for detecting local clusters, with a $10 \mathrm{~km}$ radius, similar to the surveillance area adopted in the European Union (Pittman and Laddomada, 2008) and Asian (Buranathai et al., 2007) surveillance procedures (i.e., using a $10 \mathrm{~km}$ radius zone around infected premises or flocks). Secondly, a window was chosen with a radius equivalent to an area covering $10 \%$ of all outbreaks for detecting regional clusters (Norstrom et al., 2000). Even though poultry movement was supposedly strictly controlled to remain within the surveillance areas, the virus could have been transmitted outside the surveillance zones by wild birds. Given the size and shape of the study area, the maximum spatial window covering $10 \%$ of total outbreaks was selected to avoid scanning outside the study area (Sauders et al., 2003).

The temporal window was also set to be less than $50 \%$ of the study period (Kulldorff, 2006). The maximum temporal scanning window was determined by a temporal risk window, which is defined as the period that an infected cluster remains infectious and the virus could be spread to other clusters. In this study, the maximum temporal scanning window (temporal risk window) was assumed to be 30 days, starting one day after a initially defined first lesion date and ending 21 days (the incubation period) after a slaughter and disinfection period (assumed to be 9 days).

Other options in the SaTScan software were selected as follows: (i) retrospective analysis was selected to allow both "alive" and "historic" clusters to be detected; (ii) scan for high rates was selected for cluster detection; (iii) time aggregation was not applied, as the maximum temporal scanning window was set at 30 days and the disease did not vary considerably over time; (iv) the number of Monte Carlo simulations was set at 999; and (v) the most likely clusters and non-overlapping secondary clusters were selected. For mapping purposes, significant clusters $(\mathrm{P}<0.05)$ were classified into five risk levels, according to the relative risk obtained from the analysis result.

\section{Role of wild birds in H5N1 spread}

To deduce the role of wild birds in H5N1 spread over long distance, bird migration patterns were compared with the disease trajectory. All regional and local clusters indentified along flyways that follow the migration routes were considered potentially related to wild birds. To deduce the role of wild birds in $\mathrm{H} 5 \mathrm{~N} 1$ spread over short distance, we examined whether the local clusters were found at sites where wild birds are known to overwinter and at times when migratory birds were present.

\section{Results}

\section{Epidemic curves}

Visual inspection of the epidemic curves (Fig. 3) indicated three epidemic phases at the global level, i.e. phase I extending from week 50 (2003) to week 15 (2004), phase II from week 21 (2004) to week 16 (2005), and phase III from week 23 (2005) to week 51 (2006). Asia was involved in all disease outbreak phases, with peaks observed in week 4 (2004) during phase I, in week 41 (2004) during phase II and in week 46 (2005) during phase III. European and African outbreaks were only reported in phase III. The epidemic in Europe lasted from week 37 (2005) to week 26 (2006), with three peaks in weeks 2, 8 and 20 (2006). The epidemic in Africa overlapped with the European epidemic and lasted from week 2 to week 23 (2006), with a peak in week 12. All three epidemic phases revealed a high occurrence of $\mathrm{H} 5 \mathrm{~N} 1$ outbreaks in winter and early spring (i.e., from October to March). 

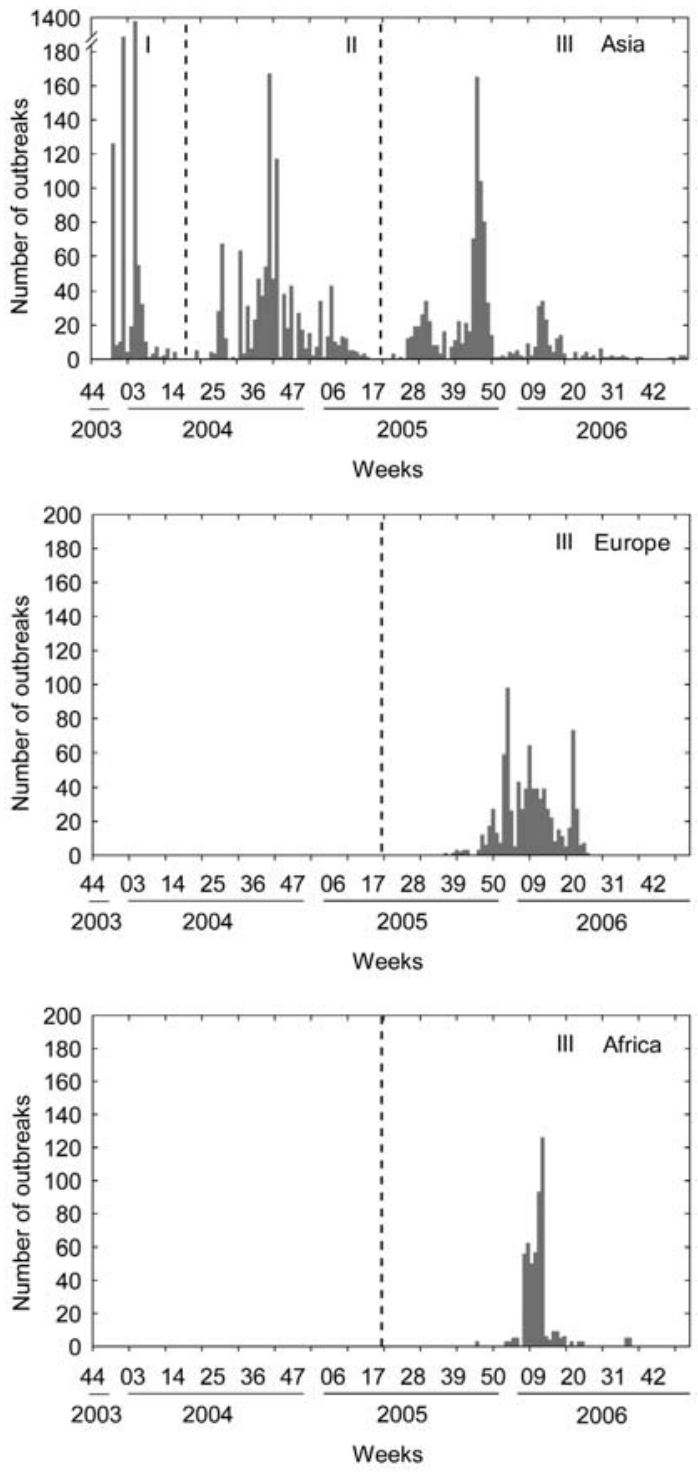

Fig. 3. Epidemic curves of reported H5N1 outbreaks from December 2003 to December 2006, displayed respectively for Asia, Europe and Africa. The three epidemic phases are separated by dashed lines.

Dynamics of space-time H5N1 clusters and correlated flyways

A total of 143 space-time clusters $(\mathrm{P}<0.05)$ were identified by the space-time permutation scan statistic, with 20, 20 and 74 local clusters, and another 8, 12 and 9 regional clusters forming for the three phases, respectively. The temporal dynamics of the identified space-time clusters in the three global epidemic phases were displayed in Figure 4, and overlaid with the five correlated flyways. (i.e., the East Asia Australian, the Central Asian, the Black Sea Mediterranean, the East Atlantic and the East Africa West Asian flyway).

\section{Global H5N1 epidemic phase I}

During the first stage of the disease outbreak, in December 2003 (Fig. 4Ia), significant clusters were identified in Indonesia, Korea and Vietnam, with low risk of infection in Southeast Asia and high risk in Korea. In January 2004 (Fig. 4Ib), the virus circulated throughout Vietnam at both local and regional level, forming six low risk clusters. Meanwhile, another low risk regional cluster occurred in southeast China. In February 2004 (Fig. 4Ic), one local cluster was identified in Indonesia, followed by one regional cluster in Thailand. Then, medium and high risk clusters started appearing in Cambodia and Japan. In April 2004 (Fig. 4Id), another high risk local cluster was identified in Thailand. During this phase, only one major migrating bird flyway (the East Asia Australian flyway) was affected.

\section{Global H5N1 epidemic phase II}

From March to May 2004 the H5N1 virus showed little activity, but then low and medium risk clusters started appearing in Thailand between June and December 2004 (Fig. 4IIa-g). Medium risk clusters were also identified in Malaysia in September (Fig. 4IId) and in Indonesia in December of that same year (Fig. 4IIg). In January and February 2005 (Fig. 4IIhi), ten disease clusters were located in Vietnam, at both local and regional level, with low and medium risk factors. The disease reoccurred in Thailand in February (Fig. 4IIi), and in Indonesia in February and March 2005 (Fig. 4IIi-j), forming one and six clusters, respectively. As during the first phase, the $\mathrm{H} 5 \mathrm{~N} 1$ virus was limited to the East Asia Australian flyway. 


\section{Global H5N1 epidemic phase III}

As in 2004, no H5N1 clusters were identified during April, May or June 2005. In July and August
2005 (Fig. 4IIIa-b), eight clusters were located in western Russia and Kazakhstan. In southeast Asia, clusters were identified in Thailand between July and September (Fig. 4IIIa-c), reappearing in south

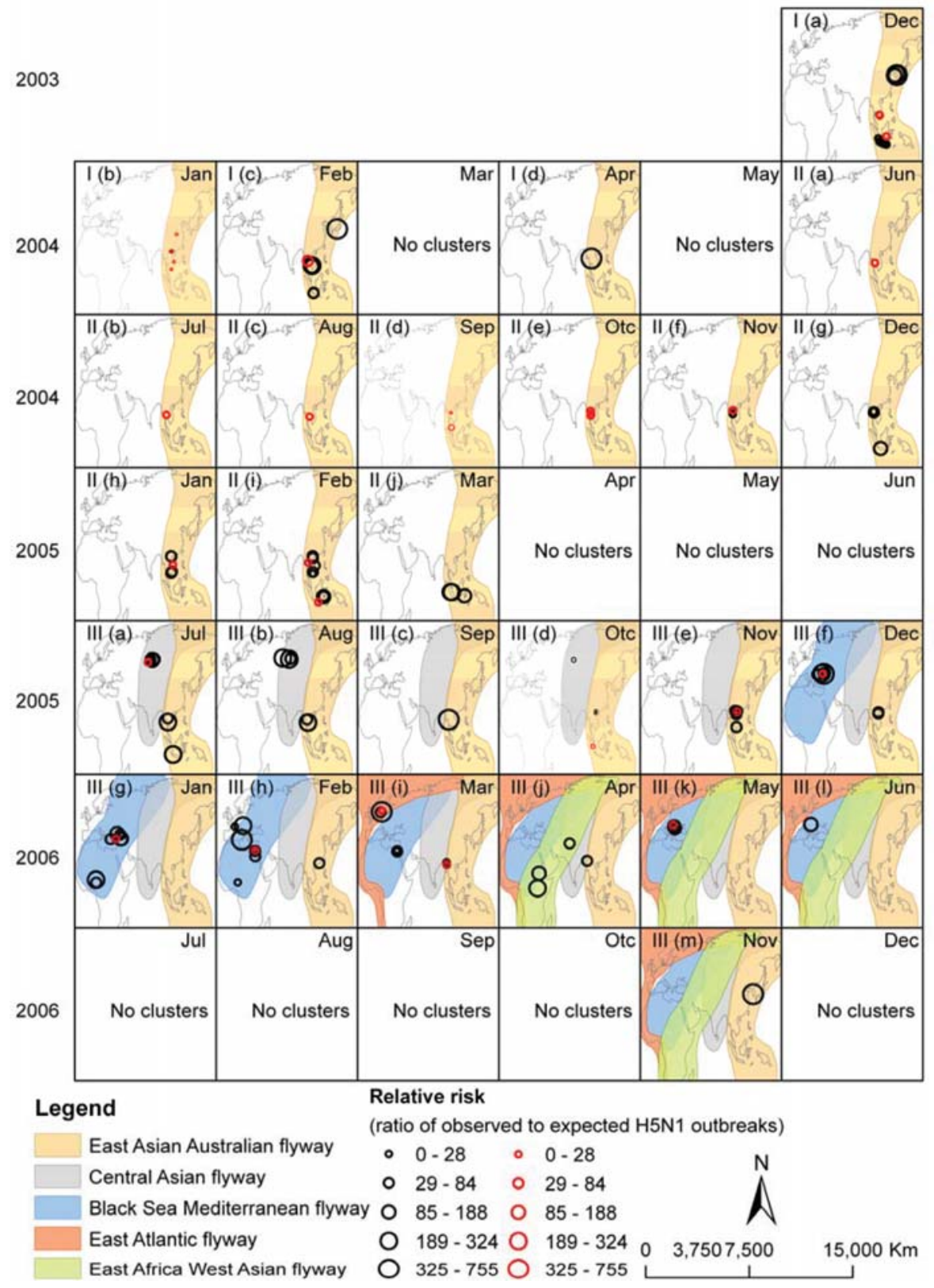

Fig. 4. Monthly dynamics of significant space-time clusters $(\mathrm{P}<0.05)$ in each epidemic phase. The size of the circle is determined by the value of the relative risk (ratio of observed to expected outbreaks) and overlaid with the correlated flyways. Black circles indicate local clusters (radius $\delta 10 \mathrm{~km}$ ) and red circles indicate regional clusters (radius $>10 \mathrm{~km}$ ). 
Indonesia during October (Fig. 4IIId). Eighteen clusters were identified in Vietnam between October and December 2005, forming either a low or a medium risk, at both local and regional level (Fig. 4IIIe-f). In October 2005, another medium risk cluster was located in western Russia (Fig. 4IIId). Thereafter, some sporadic outbreaks were reported in the Black Sea region, leading to four clusters (two of them high risk) in Ukraine and two medium risk clusters in Romania in December 2005 (Fig. 4IIIf). Disease clusters were also identified in the eastern Mediterranean in January 2006 (two of them low risk and five medium risk clusters) and in Nigeria, where three local clusters occurred in January and February 2006 (Fig. 4IIIg-h).

In February 2006 (Fig. 4IIIh), more disease clusters were located in the eastern Mediterranean region, forming one high risk local cluster in Italy and four low and medium risk clusters (at both local and regional level) in Egypt. Within the same month, two local clusters were identified in Slovenia and France, with a high and low risk factor, respectively (Fig. 4IIIh). By March 2006 there were outbreaks in northern Europe (Fig. 4IIIi), with two local clusters (medium to high risk) and one low risk regional cluster in Denmark. Another six clusters (low to medium risk) appeared in Egypt during March (Fig. 4IIIi). In April 2006 (Fig. 4IIIj), two medium risk local clusters were located in Sudan, as well as one medium risk local cluster in Pakistan. Meanwhile in Asia, one local cluster was identified in Hong Kong in February 2006 (Fig. 4IIIh), and three clusters (at both local and regional level) in Myanmar in March and April (Fig. 4IIIi-j). The disease appeared in Romania (five low to medium risk clusters) in May (Fig. 4IIIk), and in neighbouring Hungary (one medium risk cluster) in June 2006 (Fig. 4IIIl). After a relatively long period with low virus activity (July to October 2006), one final high risk local cluster was identified in Korea in November 2006 (Fig. 4IIIm).

During this third epidemic phase, the H5N1 virus circulated chronologically, via the East Asia Atlantic flyway to the Central Asian flyway, the Black Sea Mediterranean flyway, the East Atlantic flyway and finally the East Africa West Asian flyway.

Space-time H5N1 clusters along and across flyways

Based on the five identified flyways (Fig. 4), the sum of clusters occurring per month within each flyway was plotted. A chronology emerges, indicating the spread of disease clusters along and across flyways, as shown in Figure 5.

Disease clusters appeared throughout the East Asia Australian flyway during the whole study period, with peaks in December 2003, February and November 2005. In the Central Asian flyway, disease clusters started emerging in July 2005 and waned in October 2005. In the Black Sea Mediterranean flyway, clusters lasted from December 2005 to March 2006. Finally, clusters appeared in the East Atlantic and East Africa West Asian flyways in March and April 2006, respectively.

\section{Dynamics of space-time H5N1 clusters and season- al bird migration}

Six H5N1 cluster patterns were found to be associated with the seasonal migration of waterbirds (Fig. 6). In February 2004, a northbound spread of disease clusters was identified from Indonesia, via Thailand and Cambodia, to Japan. This disease pattern coincided with the wild bird spring migration northwards via the East Asia Australian flyway (Fig. 6a). During the autumn migration (August to November in 2004), the birds migrated southwards via the East Asia Australian flyway, which coincided with the disease spreading into Southeast Asia (Fig. 6b), as space-time clusters shifted from Thailand (August), via Malaysia (September), to south Indonesia (December). In the autumn of 2005 (Fig. 6c), a similar pattern was detected, in Thailand (September) and Indonesia (October), the disease clusters again following a north-south direction, overlapping with the birds' migration route via the East Asia Australian flyway. 


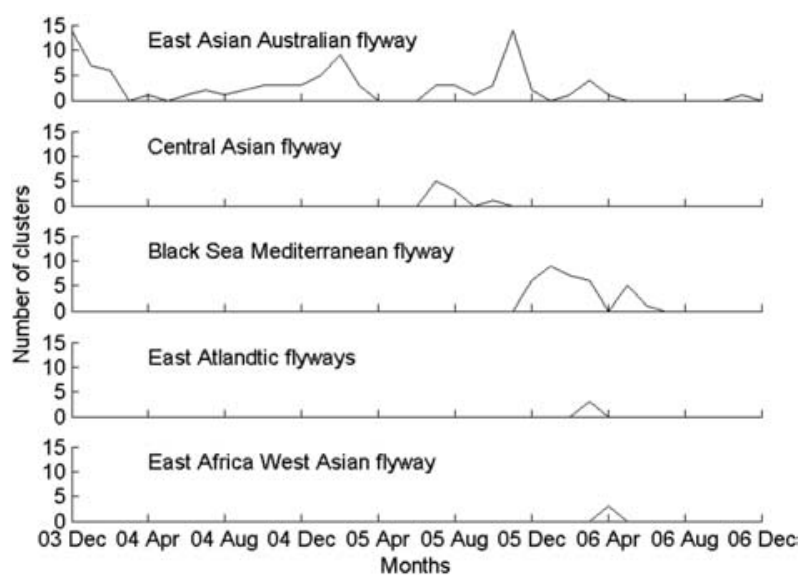

Fig. 5. Space-time H5N1 clusters along and across the flyways.

The disease clusters detected in western Russia (October 2005), the Black Sea region (December 2005) and Nigeria (January 2006), occurred in a northeast to southwest direction and coincided with peak migratory movements via the Black Sea Mediterranean flyway during autumn (Fig. 6d). During spring 2006 (Fig. 6e), space-time clusters were detected from Italy, Slovenia and neighbouring countries (February), to Denmark (March), as well as from Nigeria (February) to Denmark (March), following south-north directions. The spatio-temporal dynamics of these disease clusters correspond with the timing and direction of bird migration along both the Black Sea Mediterranean flyway and the East Atlantic flyway. In April 2006, disease clusters were first observed in Sudan, and then in Pakistan (Fig. 6f), which coincide with the direction and timing of birds migrating over the East Africa West Asian flyway.

\section{Discussion}

The H5N1 virus outbreaks can be divided into three global epidemic phases. By displaying the monthly dynamics of the space-time clusters of the disease and the matching migratory flyways of wild birds, a quantitative description is presented of $\mathrm{H} 5 \mathrm{~N} 1$ transmission at a global scale, and the possi- ble relationship between migratory birds and the spread of the disease is revealed. The H5N1 outbreaks were mainly concentrated in winter and early spring (from October to March), suggesting a seasonally higher risk of infection.

The possibility of long-distance virus spread by migratory birds

A chronology of H5N1 infections developed from the East Asia Atlantic flyway to the Central Asian flyway, the Black Sea Mediterranean flyway, the East Atlantic flyway and finally the East Africa West Asian flyway, suggesting that the H5N1 virus may be transmitted by wild birds via the different flyways. Possible reasons are that migratory birds may become infected when sharing breeding grounds in Siberia, as well as overlapping flyways creating opportunities for birds to come into contact with each other.

The correlation between disease cluster patterns and seasonal wild bird migration suggests that wild birds may spread the virus over long distances. Some of our results are consistent with a previous report (Gilbert et al., 2006b), indicating that Anatidae may spread the virus from Russia and Kazakhstan to the Black Sea region during the autumn migration. We found that the virus also appeared in Nigeria after the Black Sea region had been infected. The pandemic in Nigeria occurred in January 2006, after the migratory season, but the virus may have already been present in the population of birds overwintering in Nigeria, with outbreaks not occurring until some time after the arrival of the migratory birds. A similar delay was observed in Romania, where the virus was first detected in October 2005, but the first high risk cluster was not detected till December 2005. Ducatez et al. (2006) found that the three H5N1 lineages found at two farms in Nigeria were independently introduced through routes coinciding with the migratory bird flyway. Our findings also support a previous study which suggest that the African sublineages emerged outside of Africa but 
followed the East African West Asian and Black Sea Mediterranean flyways, as at least two of the sublineages isolated in western Africa also circulated in Germany during 2006 (Ducatez et al., 2007). However, human mobility can not be excluded completely, as Nigeria imports large numbers of poultry, without rigorous bio-security safeguards, from different countries in the world (Ducatez et al., 2006). The long-distance disease spread does coincide with the seasonal pattern of bird migration over the Black Sea Mediterranean flyway.

All this evidence supports the hypothesis, that the spread of the H5N1 virus is associated with migratory movements of birds via well-known flyways. Though our study attempts to seek the role of wild birds in spreading $\mathrm{H} 5 \mathrm{~N} 1$ virus by correlative studies, this of course does not constitute "proof". In other words, human mobility cannot be ruled out as a vector in the observed patterns of virus transmission. Besides, some spatio-temporal patterns of the disease clusters, such as in Egypt (February 2006) and Sudan (March 2006), do not follow the dominant flyway direction from South to North trend expected for that time of the year, which may be caused by poultry transportation with $\mathrm{H} 5 \mathrm{~N} 1$ virus.

Latitudinal and unusual bird movements may facilitate the H5N1 virus spread as well. Gilbert et al. (2006b) suggested that the western European pandemic was caused by unusual waterfowl movements, due to unseasonably cold weather in the Black Sea area, where the virus was already established. However, detailed and localized bird movement patterns are required to further test this hypothesis, which is beyond the scope of the current study.

The possibility of short-distance virus spread by migratory birds

Migratory birds could be involved in short-distance virus spreading, especially where disease clusters were detected in overwintering areas. A large number of disease clusters was detected during winter and spring in important staging and overwintering regions for migratory waterbirds (http://ram-
sar.wetlands.org/Default.aspx), such as Xuan Thuy Natural Wetland Reserve in Vietnam, Chany Lakes in Russia, Kizilirmak Delta in Turkey, Aquatic-cliff complex of Karadag in Ukraine, South Funen Archipelago in Denmark, Vendicari in Italy and Maldunba Lake in Nigeria. By sharing staging and overwintering sites, migratory waterbirds come into contact with other flocks of birds, as well as with free-ranging poultry (Gilbert et al., 2006a; Onozuka and Hagihara, 2008), facilitating the spread of disease. In addition, the outbreaks in western Europe and central Asia (Fig. 2), showed few or no infections in poultry, suggesting that wild birds have to play a role in the virus transmission.

Infected migratory birds may facilitate the virus spread by contaminating overwintering sites, as the virus may survive without a host for extended periods, especially at low temperatures. Stallknecht et al. (1990) determined that water with an initial concentration of $1 \times 10^{6} \mathrm{TCID}_{50} \quad(50 \%$ tissue culture infective dose) could remain infectious for up to 207 days at $17^{\circ} \mathrm{C}$ or up to 102 days at $28^{\circ} \mathrm{C}$. As the $\mathrm{H} 5 \mathrm{~N} 1$ virus remains virulent in bird faeces for at least 35 days at $4^{\circ} \mathrm{C}$ and 6 days at $37^{\circ} \mathrm{C}$ (OIE, 2008), the frequent reoccurrences of disease clusters in Thailand (June to December 2004, July to September 2005), west Russia (July, August and October 2005), Vietnam (October to December 2005) and the Black Sea region (May and June 2006), suggest that local outbreaks may be caused by viruses surviving in contaminated areas.

Both local and regional clusters were assumed to be associated with epidemic risks in this study. However, we cannot exclude the possibility of some clusters, especially local ones, having no relationship with bird migration. Distinguishing epidemic risk clusters from endemic risk clusters requires extra data, such as distribution pattern of genetic lineage. This study explored the maximally possible role of wild bird in spreading H5N1 virus at either regional or local scales. We recommend confirming these findings by using genetic lineage distribution patterns to exclude endemic risks in future studies.

In conclusion, the spread of the $\mathrm{H} 5 \mathrm{~N} 1$ virus, as 


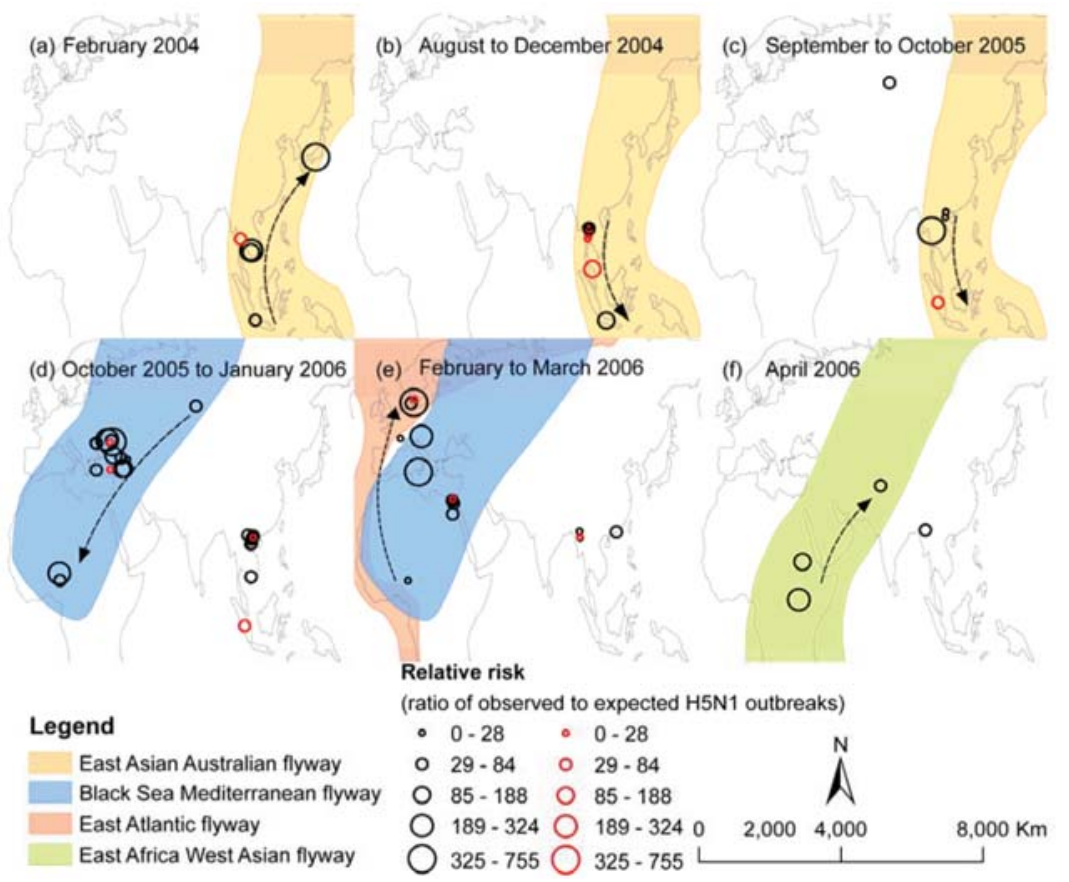

Fig. 6. Dynamics of significant space-time H5N1 clusters overlaid with correlated flyways during migratory seasons. The size of the circle is determined by the value of the relative risk (ratio of observed to expected outbreaks). Black circles indicate local clusters (radius $\delta 10 \mathrm{~km}$ ) and red circles indicate regional clusters (radius $>10 \mathrm{~km}$ ). Black arrows show the movement direction of disease clusters.

quantified by the space-time clusters, was found to be associated with the timing, location and direction of continental bird migration, suggesting that wild birds spread H5N1 over long distances. Disease clusters were also detected at sites that are known overwintering areas, and at times when these areas were frequented by migratory birds, suggesting that wild birds are involved in short distance H5N1 spread as well.

\section{Acknowledgements}

This research is sponsored by the China Scholarship Council (CSC) and the International Institute for GeoInformation Science and Earth Observation (ITC).

\section{References}

Alexander DJ, 2000. A review of avian infuenza in different bird species. Vet Microbiol 74, 3-13.
Alexander DJ, 2007. Summary of avian influenza activity in Europe, Asia, Africa, and Australasia, 2002-2006. Avian Dis $51,161-166$.

Asia-Pacific Migratory Waterbird Conservation Committee, 2001. Asia-Pacific migratory waterbird conservation strategy: 2001-2005. Kuala Lumpur, Malaysia.

Boere GC, Stroud DA, 2006. The flyway concept: what it is and what it isn't. Waterbirds around the world. GC Boere, CA Galbraith, DA Stroud (Eds). Edinburgh, UK, pp. 40-47. Brown JD, Stallknecht DE, Swayne DE, 2008. Experimental infection of swans and geese with highly pathogenic avian influenza virus (H5N1) of Asian lineage. Emerg Infect Dis 14, 136-142.

Buranathai C, Amonsin A, Chaisigh A, Theamboonlers A, Pariyothorn N, PoovorawanC Y, 2007. Surveillance activities and molecular analysis of $\mathrm{H} 5 \mathrm{~N} 1$ highly pathogenic avian influenza viruses from Thailand, 2004-2005. Avian Dis $51,194-200$.

Cardona CJ, Zheng X, Sandrock CE, Davis CE, 2009. Avian influenza in birds and mammals. Comp Immunol Microbiol 
Infect Dis 32, 255-273.

CDC, 2008. Principles of epidemiology: an introduction to applied epidemiology and biostatistics, Atlanta, USA, 424 pp.

Chen H, Deng G, Li Z, Tian G, Li Y, Jiao P, Zhang L, Liu Z, Webster RG, Yu K, 2004. The evolution of H5N1 influenza viruses in ducks in southern China. Proc Natl Acad Sci USA 101, 10452-10457.

Chen H, Li Y, Li Z, Shi J, Shinya K, Deng G, Qi Q, Tian G, Fan S, Zhao H, Sun Y, Kawaoka Y, 2006. Properties and dissemination of $\mathrm{H} 5 \mathrm{~N} 1$ viruses isolated during an influenza outbreak in migratory waterfowl in Western China. J Virol 80, 5976-5983.

Chen H, Smith GJD, Zhang SY, Qin K, Wang J, Li KS, Webster RG, Peiris JSM, Guan Y, 2005. H5N1 virus outbreak in migratory waterfowl: a worrying development could help to spread this dangerous virus beyond its stronghold in southeast Asia. Nature 436, 191-192.

Cooper DL, Smith GE, Regan M, Large S, Groenewegen PP, 2008. Tracking the spatial diffusion of influenza and norovirus using telehealth data: a spatiotemporal analysis of syndromic data. BMC Med 6.

Diggle P, 2003. Statistical analysis of spatial point patterns. Hodder Arnold, London, UK.

Ducatez MF, Olinger CM, Owoade AA, Landtsheer SD, Ammerlaan W, Niesters HGM, Osterhaus ADME, Fouchier RAM, Muller CP, 2006. Multiple introductions of H5N1 in Nigeria. Nature 442, 37.

Ducatez MF, Olinger CM, Owoade AA, Tarnagda Z, Tahita MC, Sow A, Landtsheer SD, Ammerlaan W, Ouedraogo JB, Osterhaus ADME, Fouchier RAM, Mulle CP, 2007. Molecular and antigenic evolution and geographical spread of H5N1 highly pathogenic avian influenza viruses in western Africa. J Gen Virol 88, 2297-2306.

Dwass M, 1957. Modified randomization tests for nonparametric hypotheses. Ann Math Stat 28, 181-187.

Feare CJ, Yasué M, 2006. Asymptomatic infection with highly pathogenic avian influenza $\mathrm{H} 5 \mathrm{~N} 1$ in wild birds: how sound is the evidence? Vet $\mathrm{J} 3$.

Gilbert M, Chaitaweesub P, Parakamawongsa T, Premashthira S, Tiensin T, Kalpravidh W, Wagner H, Slingenbergh J, 2006a. Free-grazing ducks and highly pathogenic avian influenza, Thailand. Emerg Infect Dis 12, $227-$ 234.
Gilbert M, Xiao X, Domenech J, Lubroth J, Martin V, Slingenbergh J, 2006b. Anatidae migration in the Western Palearctic and spread of highly pathogenic avian influenza H5N1 Virus. Emerg Infect Dis 12, 1650-1656.

Gilbert M, Xiao X, Pfeiffer DU, Epprecht M, Boles S, Czarnecki C, Chaitaweesub P, Kalpravidh W, Minh PQ, Otte MJ, Martin V, Slingenbergh J, 2008. Mapping H5N1 highly pathogenic avian influenza risk in Southeast Asia. Proc Natl Acad Sci USA 105, 4769-4774.

Keawcharoen J, van Riel D, Amerongen G, Bestebroer T, Beyer WE, van Lavieren R, Osterhaus ADME, Fouchier RAM, Kuiken T, 2008. Wild ducks as long-distance vectors of highly pathogenic avian influenza virus (H5N1). Emerg Infect Dis 14, 600-607.

Kilpatrick AM, Chmura AA, Gibbons DW, Fleischer RC, Marra PP, Daszak P, 2006. Predicting the global spread of H5N1 avian influenza. Proc Natl Acad Sci USA 103, 19368-19373.

Kulldorff M, 2006. SaTScan User Guide. StatScan, Boston, USA, 102 pp.

Kulldorff M, Heffernan R, Hartman J, Assuncao R, Mostashari F, 2005. A space-time permutation Scan Statistic for disease outbreak detection. PLoS Med 2, 216224.

Lee C-W, Suarez TMT, Sung H-W, Kwon Y-K, Lee Y-J, Choi J-G, Joh S-J, Kim M-C, Lee E-K, Park J-M, Lu X, Katz JM, Spackman E, Swayne DE, Kim HJ, 2005. Characterization of highly pathogenic H5N1 avian influenza A viruses isolated from South Korea. J Virol 79, 3692-3702.

Lee Y-J, Choi Y-K, Kim Y-J, Song M-S, Jeong O-M, Lee E-K, Jeon W-J, Jeong W, Joh S-J, Choi K-s, Her M, Kim M-C, Kim A, Kim M-J, Lee Eh, Oh T-G, Moon H-J, Yoo D-W, Kim J-H, Sung M-H, Poo H, Kwon J-H, Kim C-J, 2008. Highly pathogenic avian influenza virus (H5N1) in domestic poultry and relationship with migratory birds, South Korea. Emerg Infect Dis 14, 487-490.

Li KS, Guan Y, Wang J, Smith GJD, Xu KM, Duan L, Rahardjo AP, Puthavathana P, Buranathai C, Nguyen TD, Estoepangestie ATS, Chaisingh A, Auewarakul P, Long HT, Hanh NTH, Webby RJ, Poon LLM, Chen H, Shortridge KF, Yuen KY, Webster RG, Peiris JSM, 2004. Genesis of a highly pathogenic and potentially pandemic H5N1 influenza virus in eastern Asia. Nature 430, 209-213.

Liu J, Xiao H, Lei F, Zhu Q, Qin K, Zhang X-w, Zhang X-1, 
Zhao D, Wang G, Feng Y, Ma J, Liu W, Wang J, Gao GF, 2005. Highly pathogenic H5N1 influenza virus infection in migratory birds. Science 309, 1206.

Normile D, 2006. Evidence points to migratory birds in H5N1 spread. Science 311, 1225.

Norstrom M, Pfeiffer D, Jarp J, 2000. A space-time cluster investigation of an outbreak of acute respiratory disease in Norwegian cattle herds. Prev Vet Med 47, 107-119.

OIE, 2005. Avian Influenza. Terrestrial Animal Health Code. OIE, Paris, France.

OIE, 2008. Disease Card. Avian Inluenza. OIE, Paris, France. Olsen B, Munster VJ, Wallensten A, Waldenstro J, Osterhaus ADME, Fouchier RAM, 2006. Global patterns of influenza A virus in wild birds. Science 312, 384-388.

Onozuka D, Hagihara A, 2008. Spatial and temporal dynamics of influenza outbreaks. Epidemiology 19, 824-828.

Oyana TJ, Dai D, Scott KE, 2006. Spatio-temporal distributions of reported cases of the avian influenza H5N1 (bird flu) in Southern China in early 2004. Avian Dis 50, 508-515.

Pearl DL, Louie M, Chui L, Dore K, Grimsrud KM, Leedell D, Martin SW, Michel P, Svenson LW, Mcewen SA, 2006. The use of outbreak information in the interpretation of clustering of reported cases of Escherichia coli $\mathrm{O} 157$ in space and time in Alberta, Canada, 2000-2002. Epidemiol Infect 134, 699-711.

Pei Y, Swinton J, Ojkic D, Sharif S, 2009. Genetic characterization of two low pathogenic avian influenza virus H5N1 isolates from Ontario, Canada. Virus Genes 38, 149-154.

Pfeiffer DU, Minh PQ, Martin V, Epprecht M, Otte MJ, 2007. An analysis of the spatial and temporal patterns of highly pathogenic avian influenza occurrence in Vietnam using national surveillance data. Vet J 174, 302-309.

Pittman M, Laddomada A, 2008. Legislation for the control of avian influenza in the European Union. Zoonoses Public Health 55, 29-36.

Sauders BD, Fortes ED, Morse DL, Dumas N, Kiehlbauch JA, Schukken Y, Hibbs JR, Wiedmann M, 2003. Molecular subtyping to detect human listeriosis clusters. Emerg Infect Dis 9, 672-680.

Scott DA, Rose PM, 1996. Atlas of Anatidae populations in Africa and western Eurasia. Wetland International, Wageningen, The Netherlands, 336 pp.
Stallknecht DE, Shane SM, Kearney MT, ZwankB PJ, 1990. Persistence of avian influenza viruses in water. Avian Dis 34, 406-411.

Stroud DA, Davidson NC, West R, Scott DA, Hanstra L, Thorup O, Ganter B, Delany S, 2004. Status of migratory wader populations in Africa and Western Eurasia in the 1990s. International Wader Studies 15, 1-259.

Suarez DL, 2000. Evolution of avian influenza viruses. Vet Microbiol 74, 15-17.

Subbarao K, Katz J, 2000. Avian influenza viruses infecting humans. Cell Mol Life Sci 57, 1770-1784.

Swayne DE, Halvorson DA, 2003. Influenza. Diseases of poultry. YM Saif, HJ Barnes, JR Glisson, AM Fadly, LR McDougald, DE Swayne (Eds). Iowa State University Press, Ames, USA, pp. 135-160.

Swayne DE, King DJ, 2003. Avian influenza and Newcastle disease. J Am Vet Med Assoc 222, 1534-1540.

Tiensin T, Chaitaweesub P, Songserm T, Chaisingh A, Hoonsuwan W, Buranathai C, Parakamawongsa T, Premashthira S, Amonsin A, Gilbert M, Nielen M, Stegeman A, 2005. Highly pathogenic avian influenza H5N1, Thailand, 2004. Emerg Infect Dis 11, 1664-1672.

Ward MP, Maftei D, Apostu C, Suru A, 2008. Geostatistical visualisation and spatial statistics for evaluation of the dispersion of epidemic highly pathogenic avian influenza subtype H5N1. Vet Res 39, 22.

Weber TP, Stilianakis NI, 2007. Ecologic immunology of avian influenza (H5N1) in migratory birds. Emerg Infect Dis 13, 1139-1143.

Webster RG, Bean WJ, Gorman OT, Chambers TM, Kawaoka Y, 1992. Evolution and ecology of influenza A viruses. Microbiol Rev 56, 152-179.

WHO, 2006. Avian influenza ("bird flu”). WHO, Geneva, Switzerland.

Xu X, Subbarao K, Cox NJ, Guo Y, 1999. Genetic characterization of the pathogenic influenza A/Goose/Guangdong/1/96 (H5N1) virus: similarity of its haemagglutinin gene to those of H5N1 viruses from the 1997 outbreaks in Hong Kong. Virology 261, 15-19.

Yee KS, Carpenter TE, Cardona CJ, 2009. Epidemiology of H5N1 avian influenza. Comp Immunol Microbiol Infect Dis $32,325-340$. 